\title{
Algunas observaciones sobre nihilismo y teoría de la imagen de Fichte
}

\section{Emiliano Acosta}

\section{(2) OpenEdition \\ Journals}

Edición electrónica

URL: http://journals.openedition.org/ref/1188

DOI: $10.4000 /$ ref. 1188

ISSN: 2258-014X

Editor

EuroPhilosophie Editions

Referencia electrónica

Emiliano Acosta, «Algunas observaciones sobre nihilismo y teoría de la imagen de Fichte», Revista de Estud(i)os sobre Fichte [En línea], 18 | 2019, Publicado el 01 junio 2019, consultado el 26 enero 2021. URL: http://journals.openedition.org/ref/1188; DOI: https://doi.org/10.4000/ref.1188

Este documento fue generado automáticamente el 26 enero 2021

(C) EuroPhilosophie 


\title{
Algunas observaciones sobre nihilismo y teoría de la imagen de Fichte
}

\author{
Emiliano Acosta
}

1 En el presente artículo quiero examinar la relación entre nihilismo y teoría de la imagen (Bildtheorie) en la filosofía de Fichte. Sobre este tema se destaca dentro del ámbito de los estudios fichteanos el trabajo de Christoph Asmuth en su libro Bilder über Bilder. Bilder ohne Bilder. Eine neue Theorie der Bildlichkeit (Berlin: BWG, 2011). Asmuth, sin embargo, se concentra exclusivamente en una de las caras del concepto fichteano de nihilismo, a saber: el nihilismo entendido en sentido de Jacobi. Es esta comprensión del nihilismo fichteano - la cual por cierto es la única tematizada hasta ahora por la literatura especializada - la que Asmuth conecta con la teoría de la imagen elaborada por Fichte. Por esta razón creo necesario explorar la otra cara del nihilismo fichteano, a saber, el nihilismo que Fichte considera positiva o afirmativamente. En este sentido, el presente trabajo quiere ser entendido como una contribución para lograr una primera idea del nihilismo fichteano en su complejidad. En lo que sigue, entonces, intentaré mostrar de qué se trata el concepto positivo o afirmativo del nihilismo en Fichte y de qué modo opera el mismo en el universo fichteano de las imágenes en sentido del mundo fenoménico o de la apariencia en general (Erscheinung).

2 Mi tesis es que el nihilismo positivo o afirmativo de Fichte y su concepto de imagen son dos caras de la misma moneda, lo cual quiero expresar con la identificación 'figurativo = nulo'. El ser de la imagen se presenta entonces como una nada dentro de la filosofía de Fichte, pero esta nada no es una negación simple, sino que es una afirmación de un modo particular de ser por medio de la negación de un modo absoluto de ser, el cual Fichte lo adjudica exclusivamente a lo que él llama lo absoluto (das Absolute).

La identificación que he mencionado tiene que ser leída en ambas direcciones. De un lado el carácter de la nulidad es inherente al concepto de imagen. Desde el punto de vista de la filosofía transcendental, esta plasticidad de la realidad efectiva (ser o existir) refiere a una capacidad (poder) y a un imperativo (deber). Ambos elementos se 
concretizan en una vida que tiende y se esfuerza infinitamente por realizar la identidad entre ideal y real: el conato (Streben) fichteano. Esta vida adopta en la filosofía de Fichte la dinámica de una transformación incesante del mundo, la cual consiste esencialmente en el mejoramiento cultural, científico, religioso, moral y político del mundo. De este modo se torna visible que el postulado de la nulidad o carácter imaginario o figurativo de cuanto existe no es en modo alguno una mirada peyorativa o despreciativa del mundo, sino precisamente lo contrario: la demostración del rol esencial del mundo en la realización efectiva de la destinación de los seres racionales. Pues el ser-imagen del mundo o la ecuación 'ser-imagen = nada' es la condición de posibilidad para el proyecto moral y político de una transformación radical de la realidad que Fichte ambiciona y considera como absolutamente necesario. Dicho de otro modo: lejos de tornar irrelevante el mundo en cuanto totalidad de lo que meramente es o existe - en contraposición a la idea de un ser en sí, desde sí y por sí - el nihilismo fichteano positivo sirve para demostrar que la vida fuera del ser absoluto es necesaria, es decir: que lo otro de lo absoluto es también necesario. O, dicho de otro modo, que la substancia no es más que la totalidad de los accidentes.

Comenzaré con el concepto positivo del nihilismo en Fichte. Para esto me referiré al concepto de nihilismo de una figura central - y sin embargo olvidada, desconocida y/o malinterpretada - en la concepción del nihilismo positivo en Fichte: Jakob Hermann Obereit (1725-1798). Tal como intentaré mostrar en lo que sigue el modo en el que Obereit piensa el nihilismo permite llegar a identificar en la doctrina de la ciencia el nihilismo positivo fichteano y su conexión con la teoría fichteana de la imagen.

\section{I}

5 El término 'nihilismo' en la filosofía nos lleva inmediatamente a Jacobi. Esto no es mera casualidad, los estudios especializados sobre historia de la filosofía alemana nos enseñan que Jacobi fue el primero que utilizó este término en la filosofía - por cierto: en su condena de la doctrina de la ciencia en tiempos de la disputa sobre el ateísmo. Esto lo sabe todo el mundo y, sin embargo, tal como tantas otras verdades de la literatura especializada, no es cierto. Pues antes de Jacobi encontramos al místico alemán (también médico) Obereit que en 1787 desarrolla no sólo un concepto filosófico de nihilismo, sino además, lo cual es aún más importante, las líneas generales de lo que podríamos llamar una filosofía de la nada.

6 En los estudios sobre Fichte he encontrado solamente una mención de Obereit en los trabajos de Frederick Beiser. Sin embargo, este especialista no considera a Obereit un filósofo digno de ser estudiado, pues su concepto de nihilismo, según Beiser, es vago y su tratamiento asistemático. Además, según Beiser el nihilismo de Obereit se dirige contra Kant para demostrar la inconsistencia del proyecto kantiano de hipostasiar el sujeto o la razón pura. Es por esta razón que Jacobi debería seguir siendo considerado el "primero" en la historia de este concepto filosófico, es decir: no el primero que usa el término, sino el primero que da al nihilismo una dimensión filosófica. Sin embargo, un vistazo a El espíritu viviente de la metafísica desesperada retorna (Berlin: Decker, 1787) nos permite apreciar que Obereit es más que un fanático cristiano apesadumbrado por el ateísmo que la filosofía kantiana tiene en germen. Obereit es un pensador interesante, creativo, con un conocimiento destacable de la historia de la filosofía moderna y del debate, que luego seguirá Jacobi, acerca de los límites y las pretensiones de la razón 
moderna. Su libro muestra además que Obereit, contra la opinión de Beiser, sabía muy bien lo que quería decir con su concepto de nihilismo. Él sabía además hacia dónde quería ir con su crítica a Kant, Spinoza, Descartes y Hobbes, entre otros. La argumentación de Obereit en su discusión con las corrientes filosóficas de su tiempo están estructuradas de manera sistemática y clara (nada de la vaguedad de la que nos advierte Beiser). ${ }^{1}$

7 En su libro sobre la metafísica desesperada, Obereit ensaya una crítica de las posiciones filosóficas más importantes de su época desde Spinoza hasta Kant para de este modo mostrar principalmente 1) que ninguna de las variantes de la filosofía moderna (materialismo, espinosismo, espiritualismo, racionalismo y filosofía crítica o transcendental) ofrece un sistema consistente, 2) que todas estas filosofías si bien se dividen en dos grandes grupos, reduccionistas o extremistas, son todas testimonio de la vanidad humana, y, por último, 3) que la sabiduría suprema del ser humano consiste, por el contrario, en el reconocimiento de la fatuidad de la humanidad y del mundo. Su filosofía de la nada encarna un programa basado en principios de la fe cristiana destinado a socavar la soberbia humana - de lo que se trata, según Obereit, es de filosofar a partir de la humildad religiosa, metafísica y filosófica.

8 Su libro de 1787 ofrece, tal como Obereit anuncia en el subtítulo, un "drama crítico para una nueva crítica fundamental del espíritu de la vida". La exposición sigue, en efecto, el modelo de una obra de teatro, de la cual participan alegorías y personificaciones de la humanidad, de la metafísica, del nihilismo, de la eternidad, de distintas corrientes filosóficas de la época y también de disciplinas de la filosofía kantiana. Este drama metafísico consiste en una discusión de los personajes mencionados acerca del carácter dudoso del progreso de la metafísica moderna.

El nihilismo de Obereit, empero, representa, en lo que concierne a la presente investigación, más que una anécdota o una mera corrección historiográfica de la fecha de nacimiento del nihilismo en cuanto término filosófico. Pues su concepción de nihilismo no es ni una versión preliminar o imperfecta del nihilismo de Jacobi - algo así como un grado inferior en un proceso conceptual o en el desarrollo de una perspectiva crítica con respecto a la filosofía moderna, de modo que obereit pudiera ser considerado el primer paso de aquello que Jacobi expresa años más tarde de un modo más preciso y eficiente - ni, como ya he dicho, un acontecimiento irrelevante para una reconstrucción histórico sistemática del concepto filosófico de nihilismo.

obereit y Jacobi no comparten una misma visión acerca del problema del nihilismo en la filosofía moderna. Pues Obereit, a diferencia de Jacobi, ofrece una mirada positiva del nihilismo. Además, su nihilismo muestra puntos de contacto con la concepción positiva fichteana del nihilismo, los cuales son dignos de ser estudiados. En estos puntos de contacto encontramos similitudes entre Obereit y Fichte en lo que respecta a la concepción del carácter plástico y figurativo del mundo, del hombre, de la naturaleza y de la razón finita.

11 En cierto modo, el comienzo del libro de Obereit de 1787 repite la escenificación que Kant ofrece al inicio de su Crítica de la razón pura en la edición de 1781. El drama de la razón concebido por Obereit comienza con el llanto desesperado de la humanidad por aquello que Kant llama la metafísica, a saber: el "campo de batalla de estas controversias sin final". ${ }^{2}$ Sin embargo, Obereit no hace entrar en escena a los nómades o escépticos de Kant para que destruyan todo, sino al nihilismo, al que llama "espíritu aniquilador" (Vernichtungs-Geist) y a causa del cual la Humanidad se lamenta 
confesando que a ella "no la queda casi nada para decir salvo repetir junto con el predicador de Salomón: vanidad de vanidades". "Mira", dice la Humanidad a la Metafísica en esta primera escena del drama metafísico-religioso de Obereit, "aquí viene él de nuevo." Pero este nihilismo no habla la lengua de Jacobi, es decir, no tiene como meta la alienación humana en la filosofía o en la confusión que debilita la fe, sino que articula un mensaje redentor de la humanidad:

¿Qué haces tú [Humanidad] allí junto con la metafísica? ¿Quieres de nuevo zambullirte en especulaciones estériles y absurdas? Eso es tiempo pasado. ¡A trabajar! ¡Eso es lo que tienes que hacer para ganarte el pan para ti y para los necesitados que cada día que pasa se vuelven más! ¡Humanidad para la humanidad! ${ }^{4}$

La primera exteriorización del nihilismo en el lenguaje es un imperativo de carácter moral. El nihilismo exige a la humanidad que se comprometa con ella misma, de modo que el mundo mejore. El nihilismo de Obereit se diferencia del de Jacobi no sólo en que exige un compromiso moral con los demás, sino además en que no es ateo, sino por el contrario un ataque a la falta de fe.

Tampoco nos conduce el nihilismo de Obereit a tipo alguno de desconocimiento de Dios. El nihilismo de Obereit confiesa que él también alaba a Dios "pues sólo es él quien existe, todo lo demás es nada. Nada sin él, nada ante él. ${ }^{5}$ Nihilismo, pues, no significa aquí necesariamente ateísmo. Filosofía nihilista es para Obereit una consecuencia del reconocimiento del carácter absoluto de Dios y es el camino hacia la justificación de una praxis para el mejoramiento de la humanidad.

a idea de Obereit sobre filosofía se diferencia de la de Jacobi también en lo que concierne a la fe o al creer. Pues para Obereit la fe que libera redime no se halla en el elemento de la inmediatez. La fe está mediada por un proceso de aniquilación. De allí la recepción positiva que hace Obereit del nihilismo en cuanto espíritu aniquilador.

Según Obereit todo cuanto Dios o la Eternidad no es, es nada. La finitud no es ni para sí ni desde sí misma. Esta finitud la describe Obereit como imagen (Bild). ${ }^{6}$ Todo aquello que es es o bien desde sí o representa la esencia de sí mismo. El ser de lo que existe, de la nada, pues, se da en el representar en cuanto vida o en cuanto a imagen, expresión, espejo o instrumento de la vida. ${ }^{7}$

16 La filosofía de la nada de Obereit no se eleva al punto de vista de lo absoluto para tratar la nada de la creación, sino que al igual que Fichte concibe esta realidad desde adentro, desde la finitud misma. Se trata pues de entender el proceso de creación a través del cual la fuerza imaginativa y formadora (Bildungskraft) que es por cierto ella misma imagen, produce otras imágenes. Imagen en cuanto algo vivo, productivo. Plasticidad es lo que diferencia la finitud de la eternidad. La finitud aparece al mismo tiempo como nada e imagen, de modo tal que nihilismo y teoría de la imagen en el caso de la crítica de Obereit a la filosofía moderna son lo mismo.

17 Este carácter de nada o de imagen empero es también un signo de la tarea y del fin sumos de la humanidad. El hombre tiene que comprender la imagen en cuanto tal, esto es: en su carácter de imagen, y a través de esto debe encontrar en sí mismo la imagen de Dios en cuanto fundamento de la plasticidad figurativa de la finitud y debe modelarse a sí mismo de acuerdo a esa imagen. ${ }^{8}$

18 En la visión crítica de las imágenes y de su fundamento se halla implícito un imperativo. Este mandato presupone la capacidad de devenir algo distinto. No sólo el mundo sino también el hombre es pues un ser maleable, plástico, dispuesto por naturaleza a recibir una forma distinta de la que posee en la inmediatez de lo dado. 
Aquello que Obereit llama "impulso a ser cultivado" o "impulso formativo" (Bildungstrieb) implica "una maleabilidad esencial en dirección hacia su imagen modelo". 9

II

19 Pasemos ahora al nihilismo de Fichte. Tal como todo el mundo sabe, quien juega un papel más que crucial aquí es Jacobi. Esto explica en gran medida por qué la investigación sobre el nihilismo fichteano se concentra exclusivamente en la carta abierta de Jacobi a Fichte del año $1799 .{ }^{10}$ Hay una especie de consenso en el modo en que se debe tratar esta cuestión. Si bien los estudios sobre la relación crítica entre Jacobi y Fichte muestran ciertas diferencias entre sí, todos estos estudios tienen al menos dos puntos en común.

En primer lugar, todos definen el nihilismo fichteano a partir de la definición que Jacobi brinda y por esto restringen la noción fichteana de nihilismo a la reacción defensiva de Fichte a la carta de Jacobi, esto es: al intento de Fichte de demostrar que su doctrina de la ciencia nada tiene que ver con lo que Jacobi llama nihilismo. De allí la conclusión: la doctrina de la ciencia no es nihilismo. De allí también la clausura de una línea de investigación acerca de una noción propia, que yo llamo afirmativa, de Fichte sobre el nihilismo.

21 En segundo lugar, los estudios sobre el nihilismo de Fichte se limitan al período de los años de la disputa sobre el ateísmo, 1799-1800, a saber: desde la carta de Jacobi, conocida como, Jacobi a Fichte, hasta la publicación de La destinación del hombre de Fichte. Ahora hagamos la pregunta que queda sin hacer en estos estudios: ¿y si Fichte años más tarde cambió su noción de nihilismo? o bien: ¿y si Fichte siempre tuvo una idea de nihilismo afirmativa conectada a su anti-creacionismo, el cual sólo en sus lecciones después de Jena es tematizado por medio de su teoría de la imagen?

En sus lecciones sobre la doctrina de la ciencia de 1810 encontramos el siguiente pasaje: "estamos de acuerdo, si bien las razones son otras, con ellos [sc. Jacobi y los suyos] en que [la doctrina de la ciencia es] nihilismo." ${ }^{11}$ Este dictum sorpresivo puede ser entendido como el resultado de una discusión de Fichte consigo mismo y con el Jacobi que está en su mente. Esta discusión puede ser rastreada fácilmente a partir de 1806 en sus manuscritos. La ecuación Nihilismo $=$ Idealismo y/o Nihilismo $=$ Doctrina de la ciencia revela un cambio en la estrategia argumentativa de Fichte contra Jacobi.

Este cambio de estrategia, el cual hace posible una apropiación afirmativa o positiva del concepto de nihilismo, consiste en subvertir el significado de la palabra central en la acusación de Jacobi: nihilismo. En lugar de continuar confrontando con Jacobi, Fichte neutraliza su contendiente ofreciendo una rectificación del concepto central en el ataque de Jacobi. De este modo la discusión cambia totalmente. Ya no se trata de nihilismo sí o nihilismo no, sino del significado o los significados de la palabra y, sobre todo, de lograr una explicación a la presuposición de que la doctrina de la ciencia sea un nihilismo. Fichte parece decir: de acuerdo, mi filosofía es nihilismo, pero eso no es lo más importante, la cosa es: ¿qué significa que mi filosofía es nihilismo? o, dicho de otro modo: ¿qué significa que mi filosofía sea el significado de la palabra nihilismo?

Lo que Fichte hace aquí no es una novedad en la historia de la filosofía. Quisiera llamar a este procedimiento 'identificación subversiva'. Uno de los ejemplos más ilustrativos, 
dado que permite ver fácilmente el potencial filosófico de tal procedimiento, es la cadena de identificaciones que propone Spinoza al inicio del capítulo 16 de su Tractatus Theologico-politicus entre Dios, naturaleza, animales y hombres..$^{12}$ En lo que concierne a la filosofía transcendental podemos recordar aquí la identificación entre naturaleza y providencia que Kant con la sutilidad que lo caracteriza - y que no supo transmitir a nuestro querido Fichte - ofrece en su artículo de 1784 sobre historia universal y cosmopolitismo. ${ }^{13}$ Pero el caso del nihilismo no es, por cierto, el único que encontramos en Fichte. Pensemos en otras identificaciones subversivas tales como "sujeto = objeto" o "Yo $=$ No-Yo". ${ }^{14}$ Todas estas proposiciones son en esencia provocaciones con un solo fin: exigir al lector que piense paradoxalmente (esto es: contra la opinión dominante) y así reflexione sobre la diferencia que está siempre operando en el elemento de la identidad y en la identidad que siempre está operando en la diferencia.

La identificación subversiva entre nihilismo y doctrina de la ciencia aparece de un modo más agudo y claro en 1813:

Luego decís: idealismo $=$ nihilismo. ¡Cómo estáis encantados de haber encontrado una palabra, de la cual esperáis que nosotros nos atemoricemos! ¿Qué pasaría ahora si nosotros no fuéramos tan tontos y nos enorgulleciéramos de lo que decís? ¿Qué pasaría si consideráramos [el nihilismo] precisamente como la forma acabada y comprensiva de nuestro modo de ver las cosas? ¿Qué pasaría si nuestra filosofía fuera precisamente nihilismo, a saber: demostración rigurosa de la nada absoluta que habita fuera de la única e invisible vida llamada Dios? ¿Qué pasaría si nuestro modo de ver las cosas mostrara vuestras limitaciones y mezquindad, mostrara que vosotros no os conformáis con Dios y necesitáis de algo más que creéis poder apropiaros?"15

Como en el caso de Obereit, la filosofía de la nada de Fichte no es sino reconocimiento del carácter absoluto de Dios. De allí que para Fichte blasfemia o ateísmo en la filosofía es precisamente lo contrario de una filosofía nihilista. De este modo encontramos en Fichte al igual que en Obereit la figura de un nihilismo que no conduce al ateísmo.

Tal vez uno de los momentos de lo que en el pasaje citado arriba Fichte llama "demostración rigurosa de la nada absoluta" sea el argumento de Fichte contra la idea de la creación que se halla presente en la tradición judeo-cristiana. El núcleo del anticreacionismo de Fichte se resume en el dictum 'ab nihilo nihil fit'. Con su postulado de la imposibilidad de que haya habido una creación del universo Fichte intenta en sus lecciones de 1805 en Erlangen demostrar el carácter objetivo de la experiencia. De acuerdo con el monismo fichteano no puede haber según la esencia dos tipos distintos de ser. Si lo Absoluto es, entonces aquello que se halla fuera de ello no puede ser. La pregunta, sin embargo, no es qué tipo de ser le corresponde a lo Absoluto, sino antes bien cómo es posible que lo Absoluto aparezca, se manifieste. Dicho con otras palabras: cómo es posible que haya un mundo fenoménico y qué es lo que lo vincula con lo Absoluto. "Si hay apariencia", dice Fichte al comienzo del manuscrito conservado de la doctrina de la ciencia de 1810 , ¿cómo es esto posible?"

Resulta en verdad difícil encontrar en los textos de Fichte esa filosofía de lo Absoluto de la que se suele hablar en algunos ámbitos fichteanos. La así llamada filosofía de lo Absoluto pregunta por la apariencia que también llama imagen o esquema y que finalmente a la luz del concepto de un ser absoluto se muestra como nada. Este ser absoluto no es el objeto de la doctrina de la ciencia, sino que es lo que permite ver el objeto en cuanto tal. El ser absoluto sólo está operando como, dicho en lenguaje kantiano, un "concepto límite" (Grenzbegriff), es decir que no explica algo, ni refiere a 
una realidad suprasensible, sino que precisamente por el contrario redirecciona la reflexión hacia aquello que puede ser conocido: el mundo fenoménico. De este modo el concepto de ser absoluto como "el concepto de noúmeno" de Kant, "no es sino un concepto límite que restringe la pretensión de la sensibilidad y por esto sólo se utiliza negativamente. ${ }^{16}$ A partir del pasaje citado de las lecciones de 1810 puede comenzar a entenderse que la doctrina de la ciencia no es sino una investigación de las condiciones de posibilidad de la nada. ¿No debería ser esto motivo suficiente para poner en tela de juicio la idea de que cuando decimos "idealismo alemán" estamos diciendo algo?

El anti-creacionismo de Fichte no es por cierto una idea del segundo o tercer Fichte. Al final de la doctrina de la ciencia nova methodo Fichte critica el argumento de Dios como causa física del mundo. A la luz de la noción de nihilismo afirmativo de Fichte podemos decir que el nihilismo negativo o el nihilismo mal entendido consiste en la identificación ontológica del ser de Dios con el ser de la apariencia o de la nada. Esta identificación se concretiza cuando se coloca a Dios al final de la cadena de causalidades que constituyen el universo físico. Este modo de explicar el universo no es más, según Fichte, que el testimonio de la desesperación del hombre que no quiere ni puede aceptar que el mundo no es más que nada. "De este modo los filósofos antiguos llevaron a cabo demostraciones de la existencia de Dios a partir de la existencia mundo, esto lo hacían por desesperación, dado que lo que querían era poder detenerse en algo [cuando investigaban las cadenas de causas naturales]". ${ }^{17}$

Resulta también interesante recordar que Fichte ya en 1793, en una carta a un tal Ludwig Wilhelm Wloemer, ${ }^{18}$ ensaya un argumento en contra del creacionismo y, al igual que en varias lecciones de la doctrina de la ciencia luego de 1804, también en contra de la teoría de la emanación. La idea parece haber sido siempre la misma: es la noción del carácter todopoderoso o absoluto de Dios lo que hace imposible pensar la creación como un substrato de por sí independiente de lo Absoluto. La creación, como Fichte indica en 1805, no es un acto de lo Absoluto en cuanto tal, sino que es actividad del Yo en su universalidad en cuanto entendimiento punto. Ese Yo es imagen y crea imágenes. Todo lo que existe es nada que viene de la nada y ha sido creada por la nada. ${ }^{19}$

Pero, como he tratado de mostrar, la concepción positiva que hace Fichte del nihilismo significa un cambio en su estrategia argumentativa. Tengo la impresión de que Fichte con este cambio argumentativo encuentra la palabra justa para algo que siempre supo. Esta nueva concepción del nihilismo llega, para decirlo de algún modo, post festum. No es una declaración programática, sino un concepto que permite que lo hecho por Fichte se muestre de otro modo o muestre su verdadero rostro. Lo mismo podría decirse acerca de su teoría de la imagen. Ella atestigua que Fichte comienza a entender de qué ha estado hablando y escribiendo desde 1793.

Pues el nihilismo afirmativo fichteano ligado a la actividad productora-destructora del Yo ya está presente por ejemplo en la historia que encontramos en la GWL acerca de la génesis de la realidad en cuanto proyección de esa actividad del Yo que busca incesantemente imitar una identidad de por sí imposible de realizar. Lo real por sí queda siempre fuera del mundo del Yo. El objeto o todo lo que existe no tiene por definición substrato. ${ }^{20}$

Lo mismo puede decirse sobre la presencia ya en Jena del anti-creacionismo que es parte del nihilismo de Fichte. Pensemos en la acción capital de la que Fichte habla al comienzo de su WL-nova methodo, a saber: ese poner originario del mundo, el cual en un 
segundo momento aparece como habiendo sido ejecutado con total independencia del Yo. ${ }^{21}$

Ello no obstante, cabe aclarar que el concepto de imagen no es una mera repetición de lo mismo con otras palabras. Todo cambio en las palabras trae consigo un cambio en el sentido y significado de eso mismo que se quiere decir ahora de otro modo. El concepto de imagen aporta más claridad a la doctrina de la ciencia. Pues gracias a este concepto se entiende mucho mejor el costado positivo del carácter nulo de la realidad del cual Fichte habla incesantemente y que a muchos a llevado a hacer de Fichte un místico. Decir que la nada es esencialmente imagen significa ante todo que la nada es maleable, que la nada se deja cultivar, formar, transformar. Más importante aún: que la nada (nosotros, el mundo) estamos aquí para ser cultivados/transformados.

Por otra parte, la destinación del saber absoluto funciona también como nada y por esto como imagen o esquema para entender el otro lado activo del concepto de imagen, que la imagen, como se da en el caso de la vida de la razón, también puede ser formadora. La teoría fichteana de la imagen pone aún en mayor evidencia la plasticidad de espíritu y mundo en la doctrina de la ciencia y de este modo también comunica la nulidad de la existencia con las dimensiones práctica y teórica de la existencia.

III

Imágenes son para Fichte nada, pero no en el sentido en que esta palabra es usada por el Fichte defensivo de la Destinación del hombre. Que nosotros somos nada significa que nosotros a diferencia de lo absoluto en sí y de aquello que podría ser la cosa en sí podemos cambiar, devenir algo incluso cada vez mejor, significa que nosotros encarnamos la condición fáctica de posibilidad de la realización de la razón en la historia. No sólo el mundo, pues, existe para ser transformado, también el otro lado de la acción, lo transformador, está sujeto al devenir: pensemos en la quintuplicidad de las formas de consciencia y autoconsciencia con la que Fichte cierra su segunda serie de lecciones en $1804 .^{22}$

De este modo se añade una nueva identificación subversiva no sólo en el corpus fichteanum sino también en la historia de la filosofía: ser imagen = ser nada o figurativo = nulo o plasticidad $=$ nulidad. De este modo la filosofía de la nada de Obereit gana un nuevo significado y hace posible nuevas preguntas, tales como: ¿en qué medida sabía Fichte de la existencia del nihilismo de Obereit? ¿En qué medida es Obereit tan o más importante que Jacobi para entender el desarrollo de la doctrina de la ciencia luego de Jena?

"No hay dos sin tres", se suele decir. Y la cuestión del nihilismo de Fichte confirma este saber popular. Jacobi, Obereit, pero también Hegel nos puede ayudar a entender mejor el nihilismo Fichteano, sobre todo en lo que concierne a sus implicaciones prácticas o políticas. En sus lecciones sobre filosofía del derecho Hegel describe el espíritu aniquilador fichteano como una "furia del destruir" que sólo sabe de su existencia cada vez que destruye. ${ }^{23}$ De este modo, Hegel nos permite ver la conexión entre el carácter de imagen de la existencia y este impulso destructivo que es la vida misma del Yo fichteano. Se trata de una revolución permanente: una transformación infinita del mundo. 
39 En 1804 Fichte dice que: "de lo que se trata en la doctrina de las costumbres es de la creación absoluta pura y simplemente desde el Yo y desde la nada". Si ahora recordamos también aquello que Fichte dice en su derecho natural, a saber, que política y derecho no tienen otro fin más que la preparación para el advenimiento de la eticidad (Sittlichkeit) ${ }^{24}$, entonces se torna comprensible de qué modo están conectadas imagen y nada con la más alta destinación del ser racional. Si la existencia es un modo de la nada o una nada concreta, entonces no tiene substrato, no es más que una imagen, entonces puede ser formada y transformada. Si la existencia puede dejarse moldear, cultivar, transformar, entonces ella debe hacerlo. El paso conocido del ser al deber por medio del poder que caracteriza a la filosofía transcendental está presente aquí.

Pareciera como que la concepción fichteana de la libertad productora (esa vida que es nula, formadora y capaz de ser formada, y aniquiladora también) necesita un mundo sin substrato o insustancial - un mundo de imágenes - para poder justificarse. Un tal mundo es la condición de posibilidad para el postulado de la realización del conato infinito hacia lo infinito desconocido.

41 Ahora bien: ¿tenemos que seguir los pasos de Fichte y Obereit y hacer del mundo una nada o reducirlo a imágenes para poder justificar una praxis emancipadora de la humanidad? Ellos pensaron que un argumento semejante era necesario. La filosofía fichteana de la nada nos puede sonar un poco absurda o dar la impresión de ser el producto de alguien loco. Pero en su locura Fichte y "el bueno de Obereit", como Fichte lo llamaba, no están solos, pues: ¿no son acaso los objetos principales de la metafísica según Kant también modos de la nada? ¿Y no son estos objetos también para Kant las ideas más importantes en lo que concierne a una orientación en el pensar y en la vida? De algún modo la filosofía transcendental clásica sigue, tal como Heribert Boeder enseñaba en sus clases, aquellas palabras del sabio ginebrino:

El país de las quimeras es el único que en este mundo vale la pena ser habitado. Y es tal la nada de las cosas humanas que, con excepción del ser que por sí mismo existe, no hay nada más bello que aquello que no es. ${ }^{25}$

\section{NOTAS}

1. BEISER, F., German Idealism. The Struggle against Subjectivism 1781-1801, Cambridge, MA: Harvard University Press, 2002, p. 643, n. 10; y Hegel, New York/London: Routledge, 2005, pp. 27-29.

2. KrV A VIII.

3. OBEREIT, J. H., Der wiederkommende Lebensgeist der verzweifelten Metaphysik, Berlin: Decker, 1787, p. 14.

4. Ibid.

5. OBEREIT, J. H., Der wiederkommende Lebensgeist der verzweifelten Metaphysik, p. 15.

6. Ibid.

7. OBEREIT, J. H., Der wiederkommende Lebensgeist der verzweifelten Metaphysik, p. 27-28.

8. OBEREIT, J. H., Der wiederkommende Lebensgeist der verzweifelten Metaphysik, p. 117.

9. OBEREIT, J. H., Der wiederkommende Lebensgeist der verzweifelten Metaphysik, p. 38.

10. JACOBI, F., Iacobi an Fichte, Hamburg : bei Friedrich Perthes, 1799. 
11. WL-1801, GA II/11, 356.

12. Véase mi "Power, public opinion, right of rebellion and/or revolution in the Tractatus Theologico-Politicus: deconstructing the radicality of Spinoza's political thought, en: Landenne, Q. \& Storme, T. (eds.), L'actualité du Tractatus de Spinoza et la question théologico-politique, (serie: Philosophie Politique: Généalogies et actualités), Bruxelles: Editions de l'Université de Bruxelles, 2014, pp. 247-265.

13. IaG, AA 08:30.

14. Véase al respecto por ejemplo WLnm-K, GA IV/3, 356.

15. FW IX, 39.

16. $\mathrm{KrV}$ B 310-311.

17. WLnm-K, GA IV/3, 519. Véase también WLnm-K, GA IV/3, 355.

18. GA III/2, 15-16.

19. WL-1805, GA II/9, 288. Véase también mi "Down by law: On the structure of Fichte's Wissenschaftslehre 1805", en: Bykova, M. (ed.), The Bloomsbury Companion to Fichte, London/New York: 2020 .

20. Al respecto véase mi "Fichte: acerca del compromiso social del intelectual. Una aproximación genealógica", en: Revista de Estud(i)os sobre Fichte 8 (inv. 2014), párrafos 41-47, URL : http:// journals.openedition.org/ref/508

21. WLnm-K, GA IV/3, 344 (\$1).

22. WL-1804², GA II/8, 419-21.

23. HEGEL, G.W.F., Werke in zwanzig Bänden, Frankfurt a. M.: Suhrkamp, 1979, t. 7, p. 49.

24. GNR, GA I/4, 14

25. Rousseau, J.-J., Pensamientos de Juan-Jacobo Rousseau, Madrid: D. M. De Burgos, 1824, tomo II, pp. 249-250

\section{RESÚMENES}

This paper explores the relationship between nihilism and image theory in Fichte's philosophy. It will be shown that Fichte does not only think of nihilism in terms of Jacobi's criticism to the doctrine of science. He also provides us for an affirmative concept of nihilism, which is essentially connected with his theory of image and his theory of what we are, we can and we ought to become. In order to identify this hitherto ignored notion of nihilism in Fichte's doctrine of science, the present paper studies the nihilism concept of Jakob Hermann Obereit (1725-1798).

\section{ÍNDICE}

Keywords: Jakob Hermann Obereit, Jacobi, nihilism, theory of image

\section{AUTOR}

\section{EMILIANO ACOSTA}

Vrije Universiteit Brussel/Ghent University 